OPEN ACCESS

Edited by:

Laura Maggi,

Università degli Studi di Firenze, Italy

Reviewed by:

Angela Bonura,

National Research Council (CNR), Italy

Lorenzo Cosmi,

University of Florence, Italy

${ }^{*}$ Correspondence:

Jintao Du

9069402@qq.com

Shixi Liu

liusx999@163.com

${ }^{\dagger}$ These authors share first authorship

Specialty section:

This article was submitted to

Cytokines and Soluble

Mediators in Immunity,

a section of the journal

Frontiers in Immunology

Received: 30 January 2020

Accepted: 17 March 2021

Published: 15 April 2021

Citation:

Liu RW, Du JT, Zhou J, Zhong B, Ba L, Zhang J, Liu YF and Liu SX (2021)

Elevated microRNA-21 is a Brake of Inflammation Involved in the Development of Nasal Polyps.

Front. Immunol. 12:530488. doi: 10.3389/fimmu.2021.530488

\section{Elevated microRNA-21 Is a Brake of Inflammation Involved in the Development of Nasal Polyps}

\author{
Ruowu Liu ${ }^{1,2 \dagger}$, Jintao Du ${ }^{1,2 *}$, Jiao Zhou ${ }^{3}$, Bing Zhong ${ }^{1,2}$, Luo Ba ${ }^{4}$, Jie Zhang ${ }^{3}$, \\ Yafeng Liu ${ }^{1}$ and Shixi Liu ${ }^{1,2 *}$ \\ 1 Department of Otolaryngology-Head and Neck Surgery, West China Hospital, Sichuan University, Chengdu, China, 2 Upper \\ Respiratory Tract Laboratory of Department of Otolaryngology-Head and Neck Surgery, West China Hospital, Sichuan \\ University, Chengdu, China, ${ }^{3}$ State Key Laboratory of Biotherapy, West China Hospital, Sichuan University, Chengdu, China, \\ ${ }^{4}$ Department of Otolaryngology, People's Hospital of the Tibet Autonomous Region, Lasha, China
}

Background: CRSWNP is an inflammatory disease but the mechanism is not yet fully understood. MiR-21, a member of miRNAs, has been reported to play roles in mediating inflammation. However, the expression of miR-21 and its role in patients with CRSwNP remain elusive.

Methods: Turbinates from control subjects, uncinate processes from CRSsNP, polyp tissues from CRSwNP, and nasal epithelial cells brushed from nasal mucosa were collected. The expression of miR-21 and cytokines in nasal tissues and epithelial cells were detected by qPCR. The localization of miR-21 was detected by ISH, and its target was identified by bioinformation analysis, $\mathrm{QPCR}, \mathrm{IHC}, \mathrm{WB}$, and luciferase reporter system. The protein and mRNA of PDCD4 and NF-kB P65 were determined by WB and qPCR after miR-21 transfection in HNEpC. The role of miR-21 on cytokines was analyzed in HNEpC and nasal polyp explants.

Results: MiR-21 was upregulated in CRSwNP relative to control subjects by qPCR, which was determined mainly in nasal epithelial cells of CRSwNP by ISH. Both proinflammation cytokines (IL-1 $\beta, I L-6, I L-8, I L-25$, and TSLP) and a suppressive cytokine (IL-10) were overexpressed in the epithelial cells of CRSwNP. The expression of miR-21 was positively correlated with IL-10 and negatively correlated with IL-6, IL-8, IL-33, and TSLP in the epithelial cells of CRSWNP. As a potential target of miR-21, the expression of PDCD4 was negatively correlated with miR-21 in CRSwNP. In HNEpC, miR-21 could reduce the expression of PDCD4 at both $\mathrm{mRNA}$ and protein levels, and bioinformation analysis and luciferase reporter system confirmed PDCD4 as one target of miR-21. Furthermore, miR-21 could decrease the activation of NF- $\mathrm{kB}$ and increase IL-10 mRNA. Both SEB and LPS could elevate miR-21, with IL-25, IL-33, TSLP induced by SEB and IL$1 \beta, I L-6, I L-8$ induced by LPS, while the miR-21 could regulate the expression of IL-33, TSLP, IL-1 $\beta$, IL- 6 and IL-8 in vitro and ex vivo. Clinically, miR-21 expression was inversely correlated with the Lund-Mackay CT scores and the Lund-Kennedy scores in CRSWNP. 
Conclusion: MiR-21 could be a prominent negative feedback factor in the inflammation process to attenuate the expression of pro-inflammatory cytokines, thereby playing an anti-inflammation role in CRSwNP.

Keywords: cytokines, nasal epithelial cells, PDCD4, miR-21, chronic rhinosinusitis, nasal polyps

\section{INTRODUCTION}

Chronic rhinosinusitis (CRS) is a common inflammatory disease with approximately $10 \%$ of the adult population affected all over the world $(1,2)$. CRS is divided into two types based on the presence or absence of nasal polyp (NP): CRS without NP (CRSsNP) and CRS with NP (CRSwNP) (3). CRSwNP is a heterogeneous disease involved in a variety of structural cells, immune cells, and inflammatory mediators $(4,5)$. The etiology and pathophysiology of NP are intricate and nasal epithelial cells are known to play an important role (3). The nasal epithelium is exposed to a variety of stimuli like SEB and LPS, which cause dysfunction of the epithelium barrier and activation of epithelial cells. Cytokines, such as IL-1 $\beta$, IL- 6, IL-8, IL-25, IL-33, and TSLP are secreted by activated epithelial cells and can affect numerous immune cells, inciting inflammatory responses (6-8). However, inflammation of CRSwNP is not unlimitedly aggravating, and the functions of cytokines are strictly controlled to prevent their overaction through several mechanisms (9). IL-10 is an anti-inflammatory cytokine that can limit and ultimately terminate inflammatory responses and could be expressed by nasal epithelial cells $(10,11)$. Although the anti-inflammatory regulation of NP has been studied in recent years, the complicated mechanism remains elusive.

MicroRNAs (miR) are a class of small noncoding RNAs that regulate the expression of target genes by preventing the translation of target mRNAs or inducing their degradation, or both, depending on the level of complementarity (12). MicroRNAs are involved in the regulation of immune systems and inflammation $(13,14)$, and increasing studies show that miRNAs play an important role in the pathogenesis of NP (15-18). MiR-21, a member of microRNAs, is highlighted as potentially playing a pivotal role in regulating inflammation (1921). Notably, miR-21 may play a dynamic role in inflammatory responses, both pro-inflammatory and dampen inflammation (21). Recent studies have found that miR-21 was upregulated in asthmatic children and multiple models of experimental asthma and downregulated in cord blood monocytes from allergic rhinitis children (22-24), which indicates miR-21 is associated with airway inflammatory diseases. However, the expression and role of miR-21 in patients with CRSwNP are unclear.

In this study, we identified the expression and location of miR21 and the correlations between miR-21 and cytokines in CRSwNP. Next, we validated the expression of PDCD4, a target gene of

Abbreviations: CRS, chronic rhinosinusitis; NP, nasal polyp; CRSw/sNP, chronic rhinosinusitis with/without nasal polyp; miR, miRNA, microRNA; CT, computed tomography; qPCR, real-time quantitative PCR; ISH, in situ hybridization; LNA, locked nucleic acid; IHC, immunohistochemistry; WB, western blotting; MOD, mean optical density; NEC, nasal epithelial cell; HNEpC, Human nasal epithelial cell; IL, interleukin; LPS, lipopolysaccharide; SEB, staphylococcal enterotoxin B.
miR-21, in CRSwNP. Furthermore, we examined the role of miR21 on the nasal epithelial cells and nasal polyp explants. Finally, we evaluated the relationship between miR-21 and disease severity.

\section{METHODS}

\section{Subjects and Sample Tissues}

Subjects were recruited into the study based on the diagnostic criteria of CRS including medical history, physical examination, nasal endoscopy, and computed tomography (CT) scan of the sinuses (3). Unilateral rhinosinusitis, antrochoanal polyps, allergic fungal rhinosinusitis, cystic fibrosis, or immotile ciliary disease were excluded from the study. Before surgery, the severity of nasal symptoms was evaluated according to SNOT-20, Lund-Mackay CT scores, and Lund-Kennedy endoscopic scores (3). The atopic status of the patient was confirmed by a skin prick test. The diagnosis of asthma was performed by the pneumologist. Patients had not used oral or nasal corticosteroids and topical medication for more than 4 weeks before surgery. Turbinate tissues were obtained from control subjects during septoplasty. Uncinate process tissues and NP tissues were collected from patients with CRSsNP and CRSwNP respectively through functional endoscopic sinus surgery. All samples were divided into 3 parts: one part was preserved in RNA-latter and snap-frozen at $-20^{\circ} \mathrm{C}$ for total RNA isolation; and the other part was fixed in $4 \%$ paraformaldehyde, gradiently dehydrated, and subsequently embedded in paraffin wax or frozen in O.C.T. Compound (SAKURA, Northbrook, USA) at $-80^{\circ} \mathrm{C}$. The remainder was immediately frozen in liquid nitrogen for isolation of proteins.

Patient characteristics are shown in Table 1. This study was approved by the Medical Ethics Committee of the West China Hospital of Sichuan University (No.: WCH2015-199) and was conducted in accordance with approved institutional guidelines. Informed written consent was obtained from all patients prior to the study.

TABLE 1 | Patient characteristics and symptom scores.

\begin{tabular}{lccc}
\hline & Control & CRSsNP & CRSwNP \\
\hline $\mathrm{N}$ & 15 & 10 & 45 \\
Age, median (range) & $33(18-46)$ & $43(19-57)$ & $46(18-62)$ \\
Female/male & $1 / 14$ & $3 / 7$ & $19 / 26$ \\
Asthma (n) & 0 & 0 & 6 \\
SPT $^{*}$ (n) & 0 & 3 & 14 \\
SNOT-20, median (range) & $2(0-20)$ & $11.5(2-36)$ & $9.5(1-29)$ \\
L-K $^{\#}$, median (range) & 0 & $5.5(3-10)$ & $9(2-12)$ \\
L-M $^{\$}$, median (range) & 0 & $6(0-20)$ & $15(4-24)$ \\
\hline
\end{tabular}

*skin prick test; " Lund-Kennedy score; ${ }^{\$}$ Lund-Mackay CT score. 


\section{Isolation of Nasal Epithelial Cells From Nasal Tissues}

Nasal epithelial cells (NECs) were obtained by brushing the surface with turbinate of 10 control subjects and NP of 17 CRSwNP respectively before functional endoscopic sinus surgery. The cells were collected from each subject's nostrils using nasal brushing.

\section{Isolation of Total RNA and Real-Time Quantitative PCR}

The total RNA for the specimens was isolated using miRCURY ${ }^{\mathrm{TM}}$ RNA Isolation Kit-Tissue (Exiqon, Vedbaek, Denmark), and the total RNA from cells was extracted using RNAiso Plus (Takara Biotechnology, Dalian, China) according to the manufacturer's instructions. MiRNAs were reverse transcribed to cDNA using All-in-One ${ }^{\mathrm{TM}}$ miRNA First-Strand cDNA Synthesis Kit (GeneCopoeia, Guangzhou, China). The real-time quantitative PCR (qPCR) of miRNAs was performed with All-in-One ${ }^{\mathrm{TM}}$ miRNA qRT-PCR Detection Kit (GeneCopoeia). We synthesized mRNAs to cDNA using Bimake ${ }^{\mathrm{TM}}$ All-in-One cDNA Synthesis SuperMix (Bimake, Houston, USA), and the qPCR of mRNAs was performed with Bimake ${ }^{\mathrm{TM}} 2 \mathrm{x}$ SYBR Green qPCR master mix (Bimake). Relative expression was calculated with the $2^{-\triangle \Delta C T}$ method and levels were normalized using U6 and GAPDH for miRNAs and mRNAs, respectively. The primer sequences used in this study are shown in Table 2.

\section{Fluorescence In Situ Hybridization}

The frozen specimens of the O.C.T. Compound were made into $8 \mu \mathrm{m}$-thick cryosections. Then, in situ hybridization (ISH) was performed using the Enhanced Sensitive ISH Detection kit V (FITC) (Boster, Wuhan, China) according to the protocol recommended by the manufacturer. Locked nucleic acid (LNA) probes with $5^{\prime}$-DIG and $3^{\prime}$-DIG double labeled were used for ISH. The detection probe of miR-21 was purchased from Exiqon. Positive control U6 and negative scrambled LNA probes were synthesized by Takara.

\section{Histological Analysis}

The specimens were embedded in paraffin wax then prepared as $4 \mu \mathrm{m}$-thick sections. The sections of CRSwNP were stained with hematoxylin and eosin to determine eosinophil infiltration. Three random high power fields were selected, and the number of eosinophils and total inflammatory cells were

TABLE 2 | The primer sequences used in qPCR.

\begin{tabular}{lll}
\hline Primer & \multicolumn{1}{c}{ Forward (5'-3') } & \multicolumn{1}{c}{ Reverse (5'-3') } \\
\hline GAPDH & CATCAAGAAGGTGGTGAATC & TCAAAGGTGGAGGAGTGGGC \\
IL-1 $\beta$ & AGCTACGAATCTCCGACCAG & CGTATCCCATGTGTCGAAGA \\
IL-6 & CAACCTGAACCTCCAAAGATG & ACCTCAAACTCCAAAAGACCAG \\
IL-8 & AAGGTGCAGTITGCCAAGG & CAACCCTCTGCACCCAGTIT \\
IL-10 & GCCTAACATGCTTCGAGAT & AGTCTATAGAGTCGGCACC \\
IL-25 & GGCTGTACCGTGTTCCTAAG & CTTCATGGCAAGTGGTGTAG \\
IL-33 & AGGAGAGAACCACCAAAG & CTGGACCCTGATATACCAAAG \\
TSLP & ATGTTCGCCATGAACTAAGGC & GCGACGCCACAATCCTGTA \\
PDCD4 & TGGATGTCCCACATTCATACTCT & TCTGGTTAAGACGACCTCCATCT \\
NF-KB & ATGTGGAGATCATTGAGCAGC & CCTGGTCCTGTGTAGCCATT
\end{tabular}

counted. CRSwNP can be classified into two groups: eosinophilic CRSwNP (E-CRSwNP), which was defined as the percentage of tissue eosinophils that exceeded $10 \%$ of total infiltrating cells, and non-eosinophilic CRSwNP (NECRSwNP), which did not fulfill this criterion (25). Sections were air-fixed onto microscope glass slides and air-dried overnight at $37^{\circ} \mathrm{C}$, followed by deparaffinization, hydration. Sections were then treated with $3 \%$ hydrogen peroxide at room temperature for $10 \mathrm{~min}$ and incubated with rabbit polyclonal antibody against PDCD4 (Proteintech, Wuhan, China) at $4^{\circ} \mathrm{C}$ overnight. Thereafter, sections were incubated with biotinylated secondary antibody at $37^{\circ} \mathrm{C}$ for $30 \mathrm{~min}$. Immunohistochemistry (IHC) staining was performed using Biotin-Streptavidin horseradish peroxidase Detection Kit (SP-9001, ZSGB-Bio, Beijing, China) and DAB Detection Kit (ZLI-9061, ZSGB-Bio). Three fields of view were selected for each section and images were collected under a 400-fold microscope. The mean optical density (MOD) of each image was measured through Image-Pro Plus 6.0 image analysis system, and the average value of three images of one sample is the MOD of each section.

\section{Western Blotting}

After being thoroughly grounded in liquid nitrogen, the tissues were collected for western blotting (WB). The total protein of tissues or cells was extracted in RIPA lysis buffer with a cocktail of protease inhibitors (Bimake), and then boiled for $10 \mathrm{~min}$ with SDS loading buffer. Equal amounts of protein were electrophoresed on SDS-PAGE in 10\% Tris-glycine gels and transferred to PVDF membranes (Millipore, MA, USA). Membranes were blocked with 5\% non-fat milk in tris buffered solution containing $0.05 \%$ Tween-20 at room temperature for $1 \mathrm{~h}$, followed by overnight incubation with primary antibodies against $\beta$-actin (Beyotime, Beijing, China), PDCD4 (Proteintech,

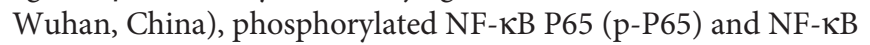
P65 (P65) (Cell Signaling Technology, Danvers, USA). After washing thrice at room temperature, the membranes were incubated with secondary antibody (Zen Bioscience, Chengdu, China) and signals were visualized by using ECL Plus Western Blotting Reagent Pack (Bio-Red, Hercules, USA). The band intensities were quantified by Fusion Solo Imaging System (VIBER LOURMAT, FRANCE).

\section{Nasal Epithelial Cell Line Culture and Transfections}

The human nasal epithelial cell (HNEpC) line used in this experiment was gifted to our laboratory by the first affiliated hospital of Sun Yat-sen University. The HNEpC cells were maintained in RPMI-1640 medium containing $10 \%$ fetal bovine serum, $100 \mathrm{U} / \mathrm{mL}$ penicillin, and $100 \mathrm{ug} / \mathrm{mL}$ streptomycin (Gibco, Paisley, UK), and incubated at $37^{\circ} \mathrm{C}$ with $5 \%$ CO2. When a $70-80 \%$ confluent monolayer appeared, the cells were used for experiments. To investigate the role of miR-21 in HNEPC, transfection was performed. MiR-21 mimics, inhibitors, and negative controls were synthesized by Genepharma (GenePharma, Shanghai, China). 50nM miR-21 mimic (Mimics), 50nM mimic negative control (mNC), 50nM 
miR-21 inhibitor (Inhibitor), and 50nM inhibitor negative control (iNC) was transfected into the cells using EndoFectin ${ }^{\mathrm{TM}}$ Max (GeneCopoeia, Guangzhou, China) for 24h, according to the manufacturer's instruction. Then, cells were treated with SEB (Toxin Technology, Sarasota, FL, USA) at concentrations $(125 / 250 / 500 \mathrm{ng} / \mathrm{ml})$ and LPS (Biosharp, Hefei, China) at concentrations $(10 / 100 / 1000 \mathrm{ng} / \mathrm{ml})$ for $24 \mathrm{~h}$. Meanwhile, cells were stimulated at various times with $250 \mathrm{ng} / \mathrm{ml}$ of SEB and 1 $\mathrm{ug} / \mathrm{ml}$ of LPS. Furthermore, cells were treated with either $250 \mathrm{ng} / \mathrm{ml}$ SEB or $1 \mathrm{ug} / \mathrm{ml}$ LPS after miR-21 transfection. All cell groups were harvested for qPCR analysis or WB. Experiments were repeated three times.

\section{Isolated Nasal Polyp Explant Culture and Transfections}

Nasal polyp tissues were isolated and cultured as described previously (26). In brief, fresh nasal polyp tissues from six CRSwNP patients were washed and suspended in RPMI-1640 medium containing $50 \mathrm{IU} / \mathrm{ml}$ penicillin, $50 \mathrm{mg} / \mathrm{mL}$ streptomycin, and $0.1 \%$ bovine serum albumin. Then the tissue was cut into smaller pieces and passed through a mesh (pore size $0.9 \mathrm{~mm}^{2}$ ) to obtain tissue fragments. Following three washings, the tissue fragments were resuspended as $0.04 \mathrm{~g}$ tissue $/ \mathrm{ml}$ culture medium, and then the fragments were divided into a 24 -well plate for explant culture. MiR-21 agomir (upgrade miR-21 mimics) and antagomir (upgrade miR-21 inhibitor) were synthesized by Genepharma. 50nM miR-21 agomir and 50nM miR-21 antagomir were transfected into explants using EndoFectin ${ }^{\mathrm{TM}}$ Max, according to the manufacturer's instruction. Then, explants were treated with either $250 \mathrm{ng} / \mathrm{ml} \mathrm{SEB}$ or $1 \mathrm{ug} / \mathrm{ml}$ LPS after transfection for 24h. Explants were collected from each well for qPCR analysis.

\section{Bioinformatics Prediction and Luciferase Reporter System}

The target genes of miR-21 were predicted by the following tools: TargetScan (http://www.targetscan.org/), miRanda (http://www. microrna.org/) and PicTar (http://pictar.mdc-berlin.de/). The luciferase reporter gene pGL3-eGFP-WT PDCD4 3'-UTR was generated, which contains the $3^{\prime}$-UTR of wild-type PDCD4, and was predicted to contain a potential miR-21 binding site (microRNA recognition element, MRE). A mutant PDCD4-1 3'-UTR at the MRE was also constructed (pGL3-eGFP-mutant PDCD4-1 3'UTR). The pRL-TK vector was used as an internal control reporter and used in combination with the experimental reporter vector to co-transfect cells.

\section{Statistical Analysis}

Statistical analyses were performed by using GraphPad Prism 8.0 (GraphPad Software, San Diego, USA). Data were presented as mean \pm standard error of mean. For nasal tissues, unpaired comparisons between multiple groups were tested by using the Kruskal-Wallis test, and the unpaired comparisons between the two groups were calculated by Mann-Whitney $U$ test. One-way ANOVA was carried out to compare the differences in cell culture data. The Spearman correlation coefficient was used to determine variable relationships. Asterisk indicates statistical significance $\left({ }^{*} \mathrm{P}<0.05,{ }^{*} \mathrm{P}<0.01,{ }^{* *} \mathrm{P}<0.001\right)$.

\section{RESULTS}

\section{The Expression and Location of miR-21 in Nasal Mucosa and NP}

To determine the expression level of miR-21, we performed a qPCR assay among 15 control subjects, 10 patients with CRSsNP, and 45 patients with CRSwNP according to the method described previously (27). The qPCR analysis showed miR-21 was significantly increased in CRSwNP compared with control subjects and CRSsNP $(\mathrm{P}<0.001)$, but it was not different between control subjects and CRSsNP ( $\mathrm{P}>0.05$ ) (Figure 1A). After being classified into two groups, the qPCR results showed miR-21 was significantly increased in E-CRSwNP and NE-CRSwNP compared with control subjects, but it was not different between E-CRSwNP and NE-CRSwNP (Supplementary Figure 1). We next sought to investigate the distribution pattern of miR-21 in nasal mucosa by fluorescence in situ hybridization. According to the fluorescence images (Figure 1B), we found that miR-21 was mainly expressed in epithelial cells of both NP and normal mucosa, with stronger signals of miR-21 in CRSwNP than that in control subjects. In addition, miR-21 was localized to the submucosal immune cells of NP but the submucosal glands of normal mucosa. The expression of miR-21 in CRSsNP was barely detected except for a few weak signals in the submucosa. Then, we detected the expression level of miR-21 in NECs from 10 control subjects and 17 patients with CRSwNP. The qPCR analysis showed that miR-21 was increased in the NECs of CRSwNP compared with that of the control subjects $(\mathrm{P}<0.01)$ (Figure 1C).

\section{Expression of Epithelial Cytokines in Nasal Tissues and Nasal Epithelial Cells}

The mRNA expressions of IL-1 $\beta$, IL-6, IL-8, IL-10, IL-25, IL-33, and TSLP among control subjects, CRSsNP and CRSwNP were assessed using qPCR. The expression levels of IL-1 $\beta$, IL-6, IL-10, and IL-25 in CRSwNP were significantly higher than in control subjects $(\mathrm{P}<0.05)$. However, no significant difference in IL-8, IL-33, and TSLP was found between control subjects and CRSwNP $(\mathrm{P}>0.05)$ (Supplementary Figure 2). Next, the expression of these cytokines in NECs from control subjects and CRSwNP were examined. IL-1 $\beta$, IL-6, IL-8, IL-10, IL-25, and the TSLP of NECs were significantly higher expressed in CRSwNP than in control subjects $(\mathrm{P}<0.05)$, and no significant difference of IL-33 was found in NECs between control subjects and CRSwNP $(\mathrm{P}>0.05)$ (Figures 2A-G).

\section{Correlations Between miR-21 Expression and Cytokines in Nasal Polyps and Epithelial Cells of NPs}

To investigate the potent role of miR-21 in CRSwNP, the correlation between miR-21 expression and cytokines in CRSwNP was examined. Pearson correlation test showed that 
A

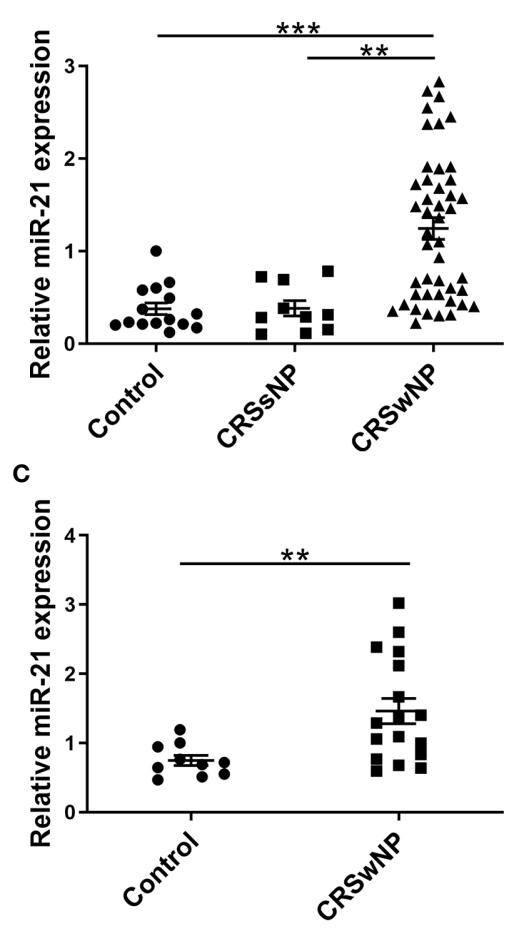

B

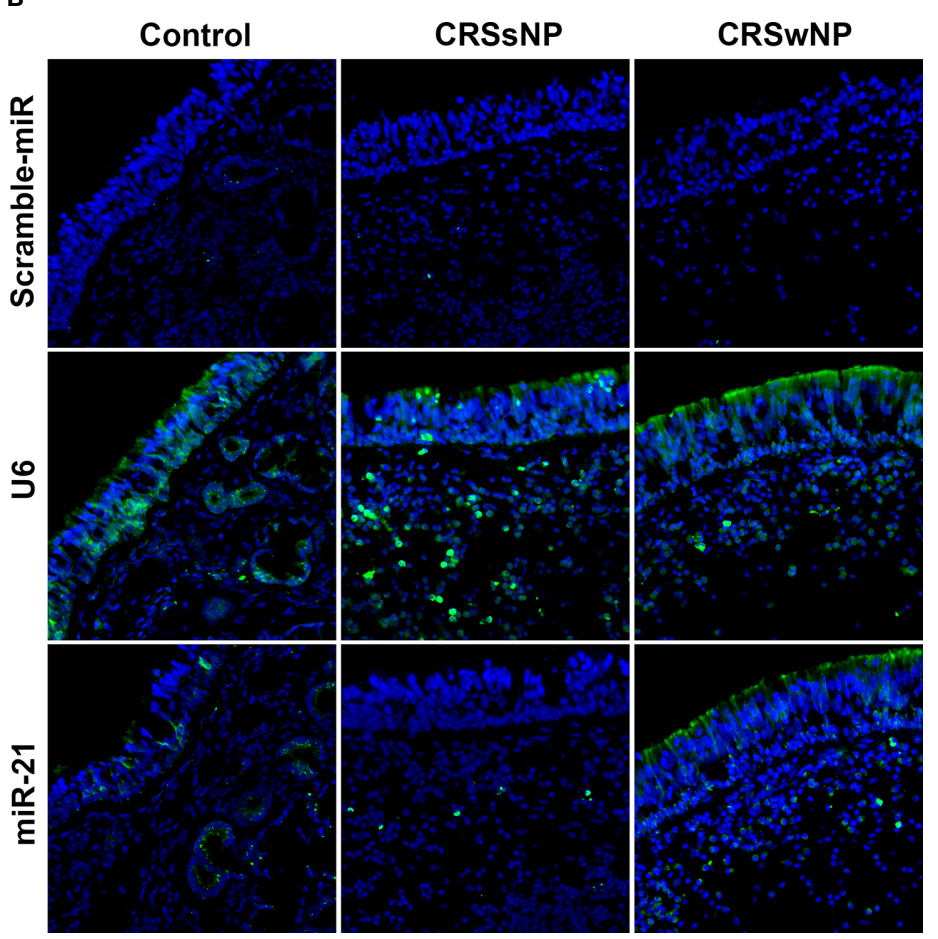

FIGURE 1 | The expression and location of MiR-21 in different nasal tissues. (A) The expression of miR-21 was analyzed by qPCR assay among control subjects $(n=15)$, CRSsNP $(n=10)$ and CRSwNP ( $n=45)$. (B) The distribution pattern of miR-21 was investigated by fluorescence ISH in the control group, CRSsNP, and CRSwNP. Scramble-miR means negative control, U6 means positive control. (C) The expression of miR-21 in NECs was analyzed by qPCR assay between control subjects $(n=10)$ and CRSwNP $(n=17)$. Kruskal-Wallis test and Mann-Whitney $U$ test was used for comparison among multiple groups and between two groups. The asterisk indicates statistical significance, ${ }^{\star *} \mathrm{P}<0.01,{ }^{* \star *} \mathrm{P}<0.001$.

miR-21 may be positively related with IL-10 but be negatively related with IL-1 $\beta$, IL-6, IL-8, IL-33, and TSLP in NP tissues, although the correlations were not significant $(\mathrm{P}>0.05)$ (Supplementary Figure 3). Then, the correlations between miR-21 expression and cytokines in E-CRSwNP and NECRSwNP were examined respectively, without significant differences in E-CRSwNP and NE-CRSwNP. (Supplementary Figure 4). Furthermore, the correlations between miR-21 expression and cytokines were examined in NECs of NP. The results showed that miR-21 was positively related with IL-10 and negatively related with IL-6, IL-8, IL-33, and TSLP $(\mathrm{P}<0.05)$. There was no significant correlation between miR-21 and IL-1 $\beta$ or IL-25 $(\mathrm{P}>0.05)$ (Figure 3$)$. We thus speculated that upregulated miR-21 in the epithelium might have the function of anti-inflammation in CRSwNP.

\section{Expression of PDCD4 in Patients With CRSwNP}

A previous study confirmed that elevated miR-21 could promote IL-10 production and block NF- $\mathrm{KB}$ activation via decreasing PDCD4 expression to limit inflammation (28). However, the expression of PDCD4 in nasal mucosa is unclear. Thus, we measured its expression in nasal tissues from control subjects and patients with CRSwNP. IHC staining showed that PDCD4 was expressed in the epithelium and subepithelial layers of both
NPs and normal tissues (Figure 4A). The MOD analysis of IHC and densitometric analysis of WB demonstrated that the PDCD4 protein remarkably decreased in CRSwNP compared with control subjects $(\mathrm{P}<0.05)$ (Figures 4B-D). Consistently, PDCD4 mRNA expression was significantly lower in CRSwNP than in control subjects $(\mathrm{P}<0.001)$ (Figure 4E). Furthermore, we found that PDCD4 expression was negatively correlated with miR-21 in CRSwNP $(\mathrm{P}<0.01)$ (Figure 4F). The negative correlation between miR-21 and PDCD4 in the nasal epithelium of CRSwNP indicated that miR-21 could regulate PDCD4 expression in nasal epithelial cells.

\section{MiR-21 Inhibits the Expression of PDCD4 by Targeting Its mRNA}

After in vitro transfecting, miR-21 mimics or inhibits HNEpC. $\mathrm{WB}$ and $\mathrm{qPCR}$ analysis showed that PDCD4 protein and mRNA were significantly inhibited by the overexpression of miR-21 $(\mathrm{P}<0.05)$ (Figures 5A-C). To investigate whether PDCD4 is a target gene of miR-21, we used bioinformatic tools including TargetScan, miRanda, and PicTar to identify the potential miR21 binding sites in $3^{\prime}$-UTR of PDCD 4 mRNA (Figure 5D). These results imply that miR-21 could inhibit the expression of PDCD4 mRNA and protein via binding its mRNA.

Co-transfection of the PDCD4 luciferase reporter vector and the pRL-TK vector with miR-21 mimic in HEK 293 cells resulted 

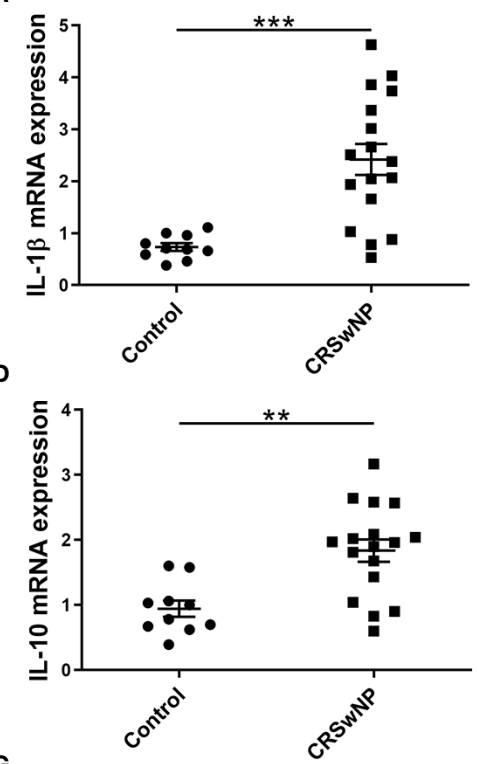

G

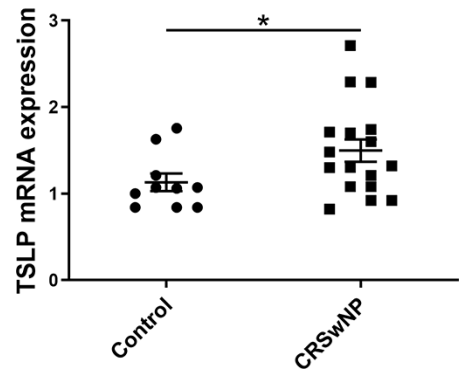

B
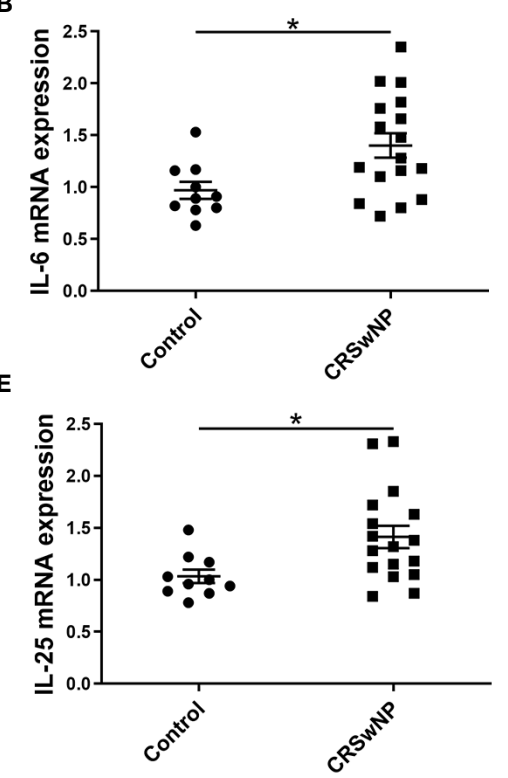

C
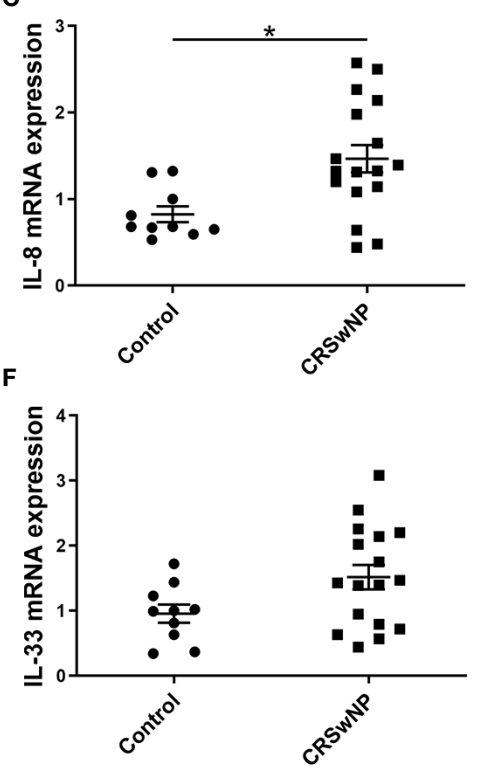

FIGURE 2 | The relative expression level of epithelial cytokines in the epithelial cells of NPs. The mRNA expression of (A) IL-1ß, (B) IL-6, (C) IL-8, (D) IL-10, (E) IL-25, (F) IL-33, and (G) TSLP in NECs were measured by qPCR and compared between control subjects $(n=10)$ and CRSwNP $(n=17)$. Mann-Whitney U test was used for comparison between the two groups. The asterisk indicates statistical significance, ${ }^{\star} P<0.05,{ }^{\star \star} P<0.01,{ }^{\star \star \star} P<0.001$.

in a significant reduction in luciferase activity relative to the scrambled control, while co-transfection with the miR-21 inhibitor resulted in significantly increased luciferase activity (Figure 5E). Furthermore, co-transfection with miR-21 mimic and the miR-21 inhibitor also restored the expression of eGFP (Figure 5E). Moreover, luciferase activity was unaffected when the MRE in PDCD4 3'-UTR was mutated (Figure 5D), demonstrating that PDCD4 is a direct target of miR-21 (Figure 5E). These results confirm PDCD4 as a target of miR21 in vitro. Combining the above results from $\mathrm{qPCR}$ and $\mathrm{WB}$ of CRSwNP demonstrates that miR-21 plays important roles in the formation of NP through regulating the cytokines expression 1 by targeting the PDCD4.

\section{MiR-21 Suppresses NF-kB P65 Activation and Increases IL-10 Expression in HNEpC}

To determine the effect of miR-21 on the epithelial cytokines, the protein expression of NF- $\mathrm{KB}$ subunit (P65), and the gene expression of P65, IL-1 $\beta$, IL-6, IL-8, IL-10, IL-25, IL-33, and TSLP were detected. The WB results showed that $\mathrm{p}-\mathrm{P} 65$ protein expression was significantly inhibited by miR-21 $(\mathrm{P}<0.05)$ while
P65 protein expression was not affected $(\mathrm{P}>0.05)$ (Figures 6A-C). The qPCR results showed that the mRNA expression of P65 remained consistent after miR-21 overexpression compared to miR-21 knock-down (Figure 6D). Furthermore, the qPCR results revealed that the mRNA expression of IL-10, an antiinflammatory cytokine, were elevated in the miR-21 mimic group compared with the negative control group $(\mathrm{P}<0.05)$, while the miR-21 inhibitor did not affect IL-10 $(\mathrm{P}>0.05)$ (Figure 6E). No change of other cytokines was measured after miR-21 transfection (Data not shown). Previous studies confirmed that PDCD4 could enhance the phosphorylation of $\mathrm{P} 65$ and inhibit the expression of IL-10 (28-31). These results suggest that miR-21 suppresses NF- $\kappa B$ activation and induces IL-10 mRNA expression through decreasing PDCD4 in HNEpC.

\section{Effect of miR-21 on Cytokines of Nasal Epithelial Cells After Stimulated With SEB and LPS}

We next estimated whether miR-21 could regulate the expression of cytokines in HNEpC after SEB or LPS treatment. To evaluate the appropriate dose and time response of SEB and LPS, PDCD4 

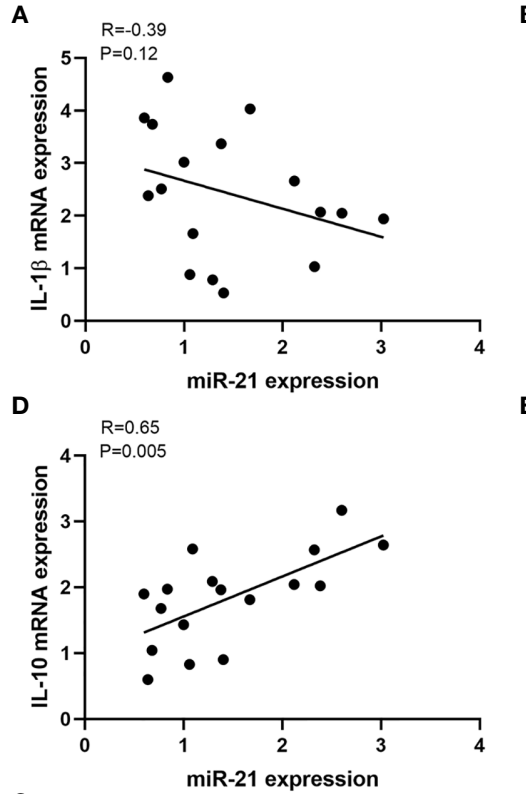

G

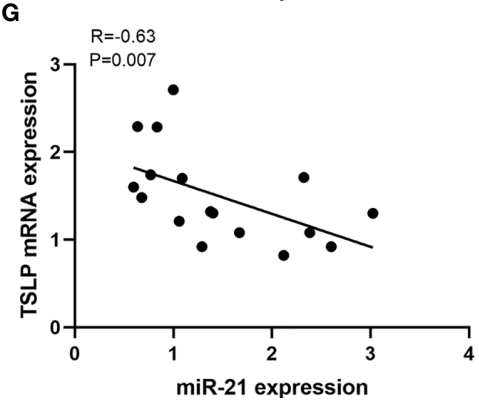

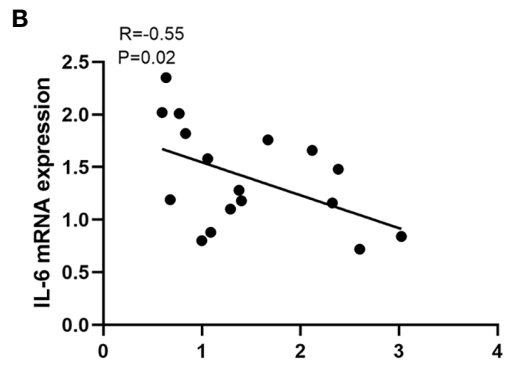

E

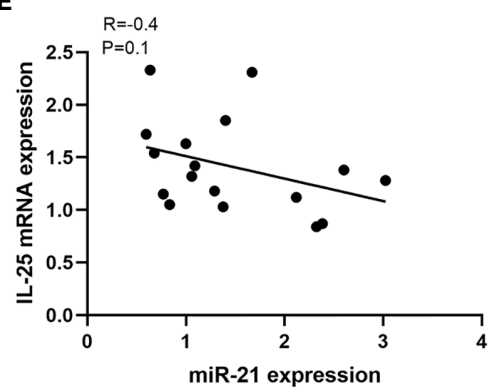

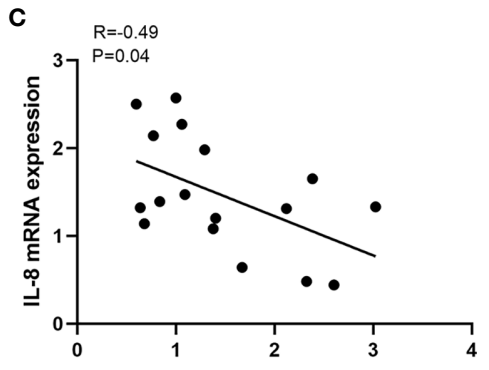

$\mathbf{F}$

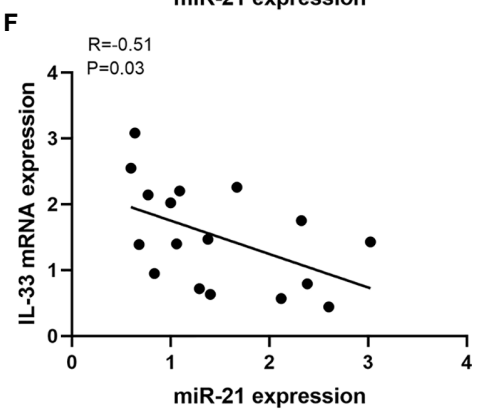

(D) IL-10, (E) IL-25, (F) IL-33, and (G) TSLP were investigated in NECs of NPs $(n=17)$. R values indicate Spearman correlation coefficients.

and p-P65 protein expression were measured at different concentrations and time-points after stimulation (Supplementary Figures 5, 6). The results showed $24 \mathrm{~h}$ of treatment with 250ng/ml of SEB and $1 \mathrm{ug} / \mathrm{ml}$ of LPS both could decrease PDCD4 protein expression and induce P65 activation (Supplementary Figures 5, 6). Accordingly, we chose the concentration and time-point of SEB and LPS to stimulate HNEpC.

Then, miR-21 transfection followed by SEB and LPS treatment was conducted. The qPCR results revealed that miR-21 was elevated by SEB and LPS stimulation, and could be enhanced by miR-21 mimics and reduced by miR-21 inhibitor $(\mathrm{P}<0.05)$ (Figures 7A, E). SEB could increase IL-25, IL-33, and TSLP mRNA expression, and LPS could increase IL-1 $\beta$, IL-6, and IL-8 mRNA expression in HNEPC $(\mathrm{P}<0.05)$ (Figures 7B-D, F-H). The effect of SEB on IL-33 and TSLP could be enhanced by miR-21 inhibitor and reduced by miR-21 mimics $(\mathrm{P}<0.05)$ (Figures 7C, D). Meanwhile, the effect of LPS on IL- $1 \beta$ and IL- 6 could be enhanced by miR-21 inhibitor and reduced by miR-21 mimics as well $(\mathrm{P}<0.05)$ (Figures 7F, G). No alteration of IL-25 or IL-8 resulting from miR-21 was observed $(\mathrm{P}>0.05)$ (Figures $\mathbf{7 B}, \mathbf{H})$. These results indicate that miR-21 plays an anti-inflammation role in HNEpC.

\section{Effect of miR-21 on Cytokines Of Cultured Nasal Polyp Explants After Stimulated With SEB and LPS}

We then explored the function of miR-21 on the expression of the cytokines of nasal polyp via an ex vivo model. MiR-21 expression was confirmed by qPCR (Figures 8A, E). SEB could increase IL-25, IL-33, and TSLP mRNA expression, and LPS could increase IL-1 $\beta$, IL-6, and IL-8 mRNA expression $(\mathrm{P}<0.05)$ (Figures 8B-D, F-H). The effect of SEB on IL-33 and TSLP could be enhanced by miR-21 antagomir and reduced by miR-21 agomir $(\mathrm{P}<0.05)$ (Figures 8C, D). Meanwhile, the effect of LPS on IL- 6 and IL- 8 could be reduced by miR-21 agomir as well $(\mathrm{P}<0.05)$ (Figures 8G, $\mathbf{H})$. We observed no significant alteration of IL-25 and IL-1 $\beta$ resulting from miR-21 ( $\mathrm{P}>0.05)$ (Figures $\mathbf{8 B}$, F). These results indicate that miR-21 is an anti-inflammation molecular involved in the development of NPs.

\section{MiR-21 Expression Correlates With Lund- Mackay Scores and Lund-Kennedy Scores}

To determine whether miR-21 correlated with disease severity in CRSwNP, we assessed the SNOT-20, Lund-Mackay, and Lund- 
A

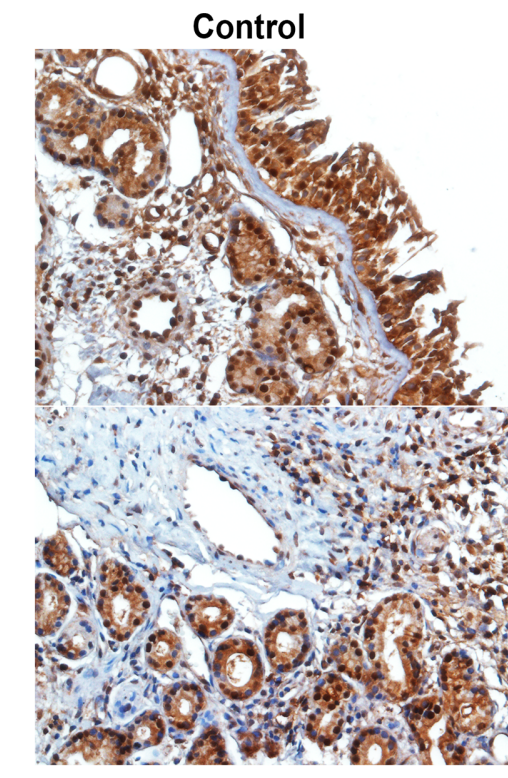

Control

C

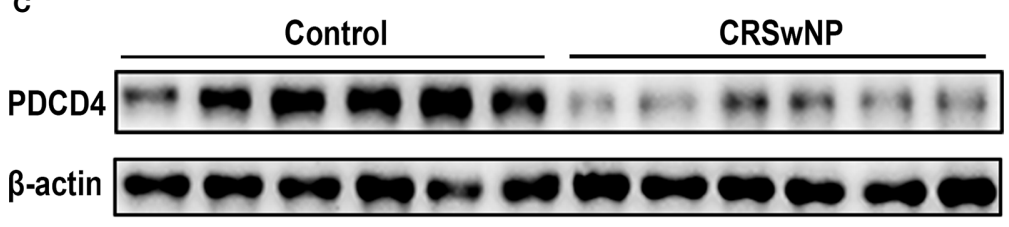

E

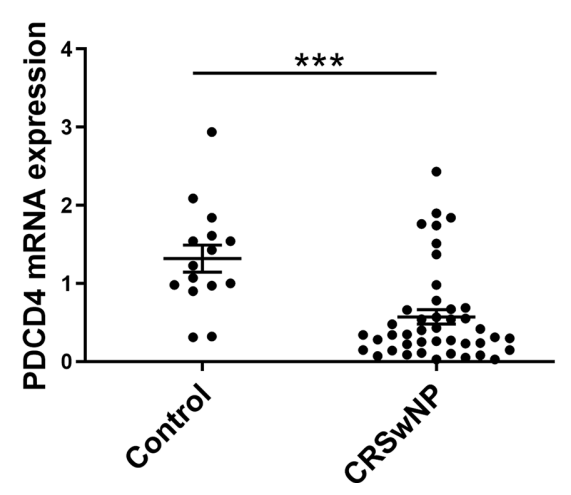

F
B

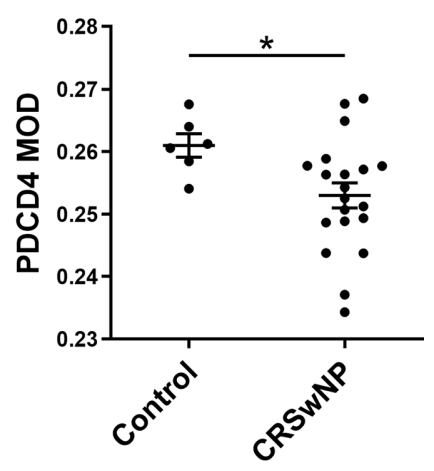

D

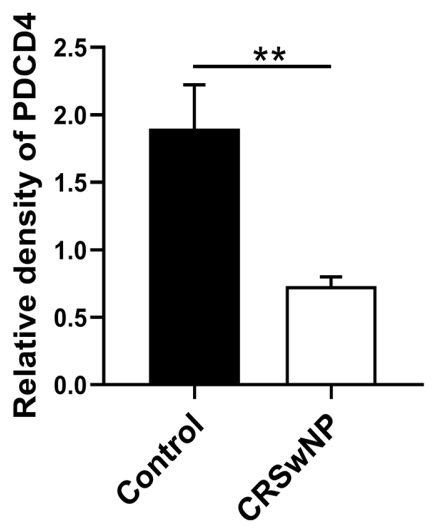

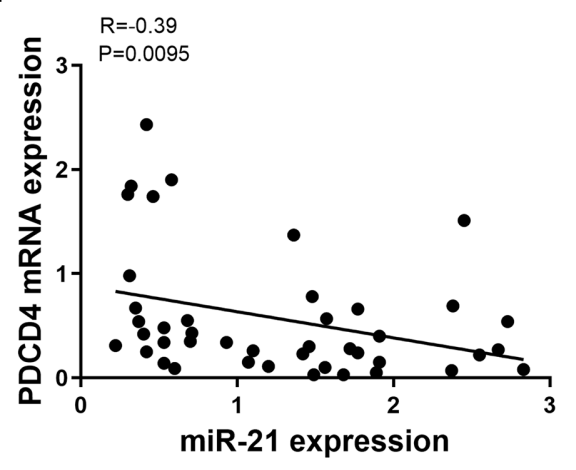

FIGURE 4 | Expression of PDCD4 in patients with CRSwNP. (A) IHC staining of PDCD4 was performed in normal tissues and NPs. (B) Comparison of PDCD4 expression were assessed through mean optical density (MOD) between control subjects $(n=6)$ and NPs ( $n=20)$. (C) PDCD4 protein expression was determined by WB in control subjects $(n=6)$ and CRSwNP $(n=6)$, with $\beta$-actin expression as a control. (D) Relative PDCD4 protein expression was quantified by densitometry based on immunoblot images. (E) Relative PDCD4 mRNA expression was measured by using qPCR between control subjects ( $\mathrm{n}=15)$ and $\mathrm{CRSwNP}$ ( $\mathrm{n}=43$ ). (F) Correlations between miR-21 and PDCD4 in CRSwNP, R values indicate Spearman correlation coefficients. Mann-Whitney $U$ test was used for comparisons between control subjects and CRSwNP. The asterisk indicates statistical significance, ${ }^{\star} \mathrm{P}<0.05 ;{ }^{\star \star} \mathrm{P}<0.01 ;{ }^{\star \star \star} \mathrm{P}<0.001$.

Kennedy scores of CRSwNP. There was no correlation between miR-21 expression and SNOT-20 scores ( $>>0.05)$ (Figure 9A), whereas miR-21 expression was negatively correlated with LundMackay scores and Lund-Kennedy scores $(\mathrm{P}<0.05)$ (Figures 9B, C). These results suggested that miR-21 is a brake of inflammation in the development of NPs.

\section{DISCUSSION}

CRSwNP is a heterogeneous disease characterized by distinct expression of inflammatory cytokines (4, 5). Currently, researchers have confirmed that nasal epithelium plays an important role in the formation of NP (3). As the first line of 
A

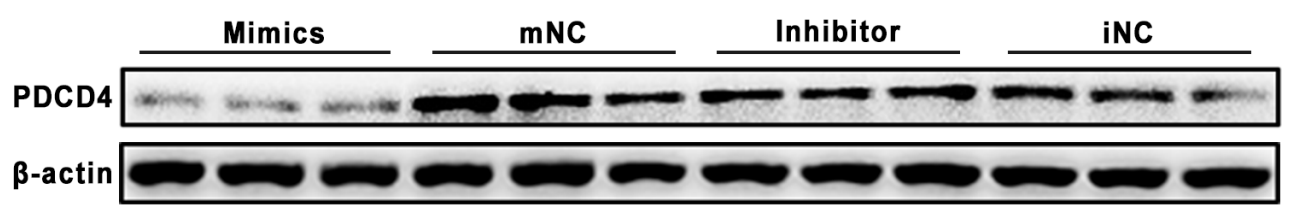

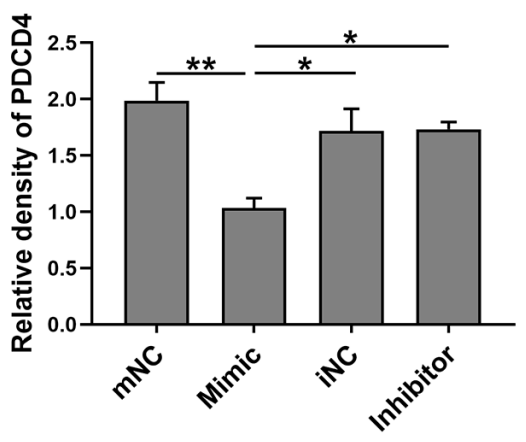

D

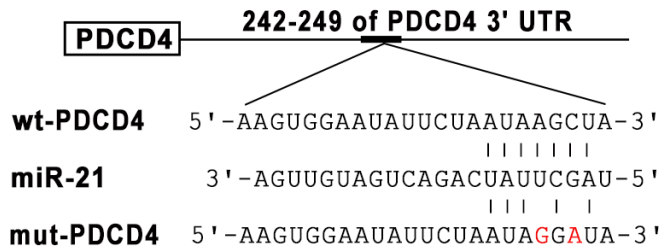

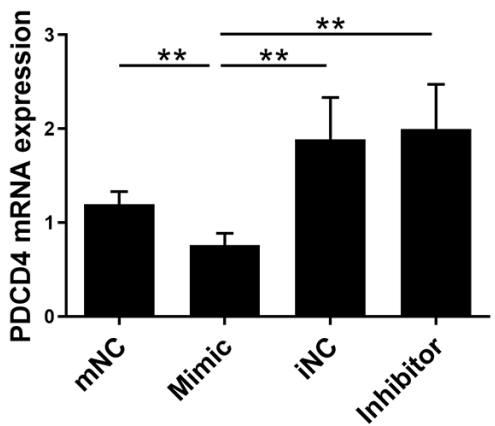

E

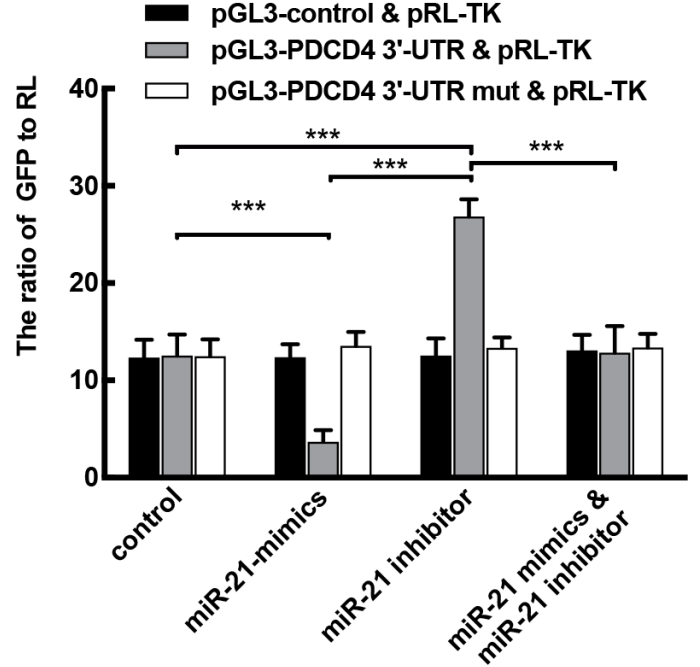

FIGURE 5 | Effect of miR-21 on the expression of PDCD4 in vitro. (A) HNEpC was transfected with miR-21 mimics (with mNC as control) and inhibitor (with iNC as control) for $24 \mathrm{~h}$. PDCD4 protein expression was determined by WB, normalized to $\beta$-actin. (B) Relative PDCD4 protein expression was quantified by densitometry based on immunoblot images. (C) PDCD4 mRNA levels were measured by qPCR. (D) The predicted miR-21 binding sites within the 3'UTR of PDCD4 mRNA. (E) Double luciferase activity assay of HEK 293 cells. After being co-transfected with the analogue of miR-21: control/miR-21 mimic/miR-21 inhibitor, and the following plasmids: pGL3-3'-UTR of control/WT/mutated PDCD4 vector and the PRL-TK vector, the ratio of GFP to RL was determined. Data were obtained in three independent experiments. One-way ANOVA was used to analyze the difference between multiple groups. The asterisk indicates statistical significance, ${ }^{\star} \mathrm{P}<0.05$; ${ }^{\star *} \mathrm{P}<0.01 ;{ }^{* \star *} \mathrm{P}<0.001$

defense of airways, the nasal epithelium is critical for maintaining homeostasis of the underlying tissue mucosa (5). Defects in the function of epithelium cause the accumulation of pathogens in the epithelial layers, and chronic exposure to pathogens induces cytokines secreted by epithelial cells which contribute to inflammation (32-35). Thus, the important treatment strategies for CRSwNP were to control inflammation and restore the function of the nasal mucosal barrier. Our study found that the expression of miR-21 was elevated in CRSwNP compared with control subjects, especially in the epithelial cells of NP. Upregulated miR-21 can inhibit activation of NF- $\kappa \mathrm{B}$ P65 and increase IL-10 expression through targeting to PDCD4 in nasal epithelial cells, which could further limit the expression of pro-inflammatory cytokines, as indicated in Figure 10. The findings of this study suggest that miR-21 is associated with anti-inflammation and is a prominent negative factor in the inflammation process that attenuates the expression of proinflammatory cytokines in nasal polyps.

MiR-21 has been implicated in a broad range of diseases, especially in human malignancies, and a growing number of studies have confirmed that miR-21 is a key switch in inflammation (21). Overexpression of miR-21 was associated with asthma (22), lumbar spinal canal stenosis (36), and dominant negative TGF- $\beta$ receptor II mice (37). In these conditions, miR-21 promoted inflammation. Conversely, miR-21 could play an antiinflammation role in lung inflammation (38), wound inflammation 
A

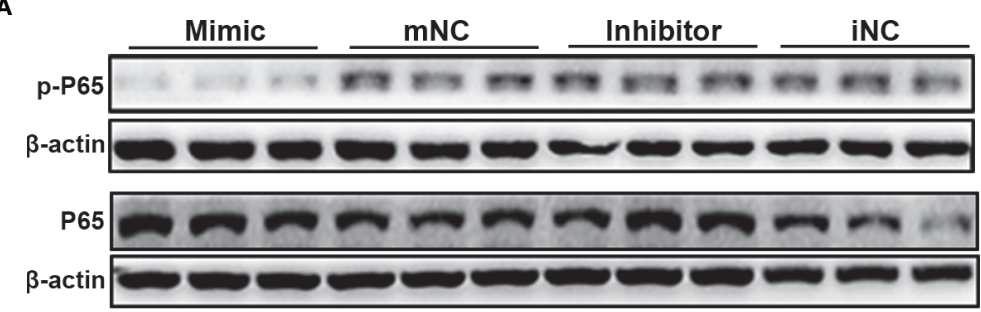

B

D
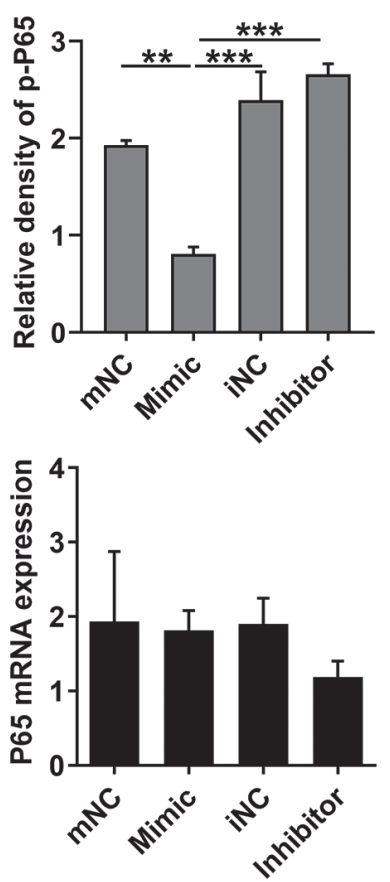

E
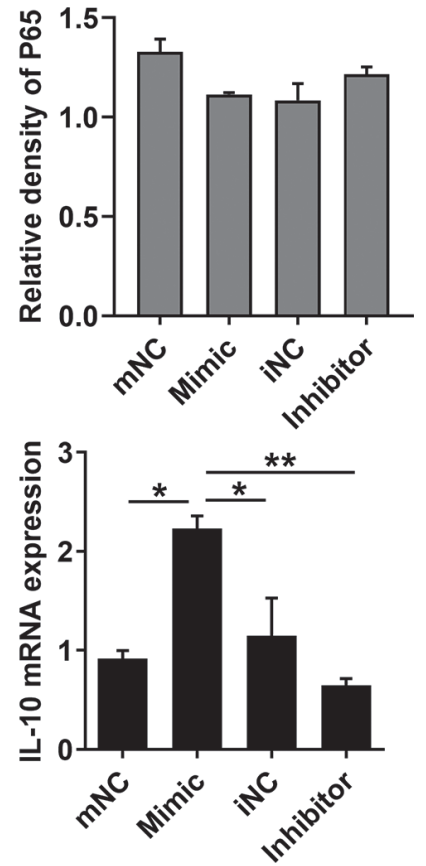

FIGURE 6 | Effect of miR-21 on the expression of NF-KB P65 and IL-10 in HNEpC. HNEpC was transfected with miR-21 mimics (with mNC as control) and inhibitor (with iNC as control) for 24h. (A) p-P65 and P65 protein expression was determined by WB, normalized to $\beta$-actin. (B, C) Relative p-P65 and P65 protein expression were quantified by densitometry based on immunoblot images. (D, E) NF-kB and IL-10 mRNA expression were measured by qPCR. Data were obtained in three independent experiments. One-way ANOVA was used to analyze the difference between multiple groups. The asterisk indicates statistical significance, ${ }^{*} P<0.05$; ${ }^{* *} P<0.01$; ${ }^{\star \star *} \mathrm{P}<0.001$.

(29), and bacterial infection mice (39). Our study confirmed that miR-21 increased in the nasal epithelium of CRSwNP compared with control subjects and that the expression of miR-21 was positively correlated with IL-10, and negatively correlated with IL-6, IL-8, IL-33, and TSLP in the epithelial cells of CRSwNP. It implied that miR-21 might have a function of anti-inflammation in CRSwNP.

Previous studies have confirmed that bolstering miR-21 levels could promote IL-10 production and inhibit the activation of NF- $\kappa \mathrm{B}$ via decreasing PDCD4 expression $(28,29)$. We hypothesized that the miR-21/PDCD $4 / \mathrm{NF}-\kappa \mathrm{B}$ and IL-10 pathways also existed in CRSwNP. We found that the protein and mRNA expression of PDCD4 was decreased in CRSwNP compared with control subjects, and PDCD4 mRNA expression was negatively correlated with miR-21. Accordingly, a link between miR-21 and PDCD4 in the epithelium of CRSwNP was identified. Through transfection assay, we found that overexpressed miR-21 could attenuate both the mRNA and protein expression of PDCD4, as indicated in bioinformatic analysis and luciferase activity assay. All these results confirmed that PDCD4 was a target of miR-21 as shown in a previous study by Cohen et al. (39). Furthermore, we explored whether the miR-21/PDCD4 axis regulated NF- $\kappa \mathrm{B}$ activation and IL-10 expression in nasal epithelial cells. Through transfection assay, we found that overexpressed miR-21 could suppress P65 activation and increase IL-10 mRNA level, which is in line with previous studies (28-31).

$\mathrm{NF}-\mathrm{\kappa B}$ is a heterodimer consisting of members of the P50 and P65 families, but the constitutional fraction of P65 acts as the regulator of inflammatory cytokines and induces the inflammatory process (40), and the production of cytokines from nasal epithelial cells was associated with the activation of NF- $\mathrm{KB}$ (40-42). Conversely, has also been reported that miR-21 could induce activation of P65 via inhibiting PDCD4 expression and could further promote the expression of inflammatory factors $(43,44)$. Furthermore, a deficiency of PDCD4 could elevate 


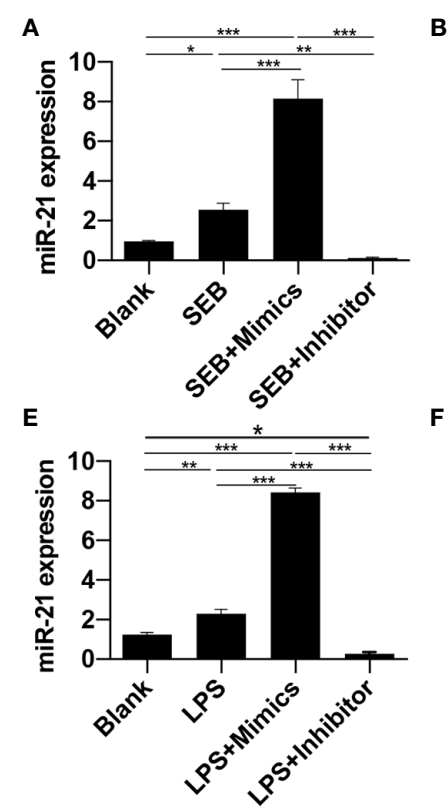

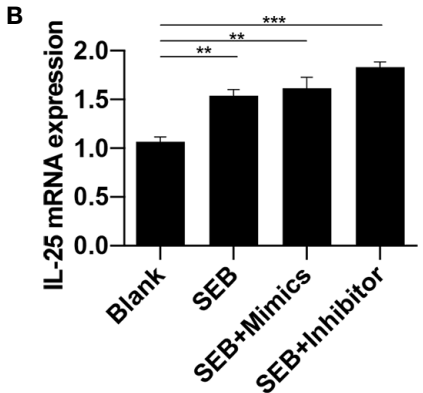

$\mathbf{F}$

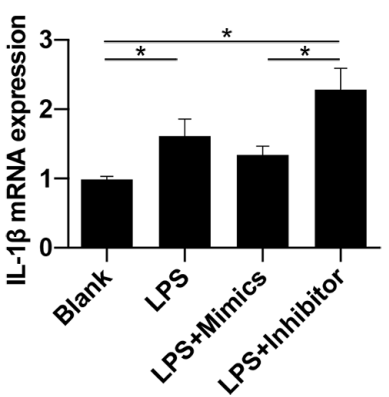

C

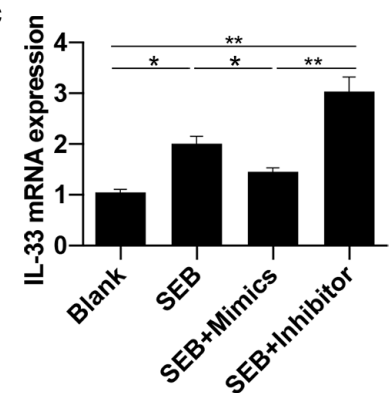

G

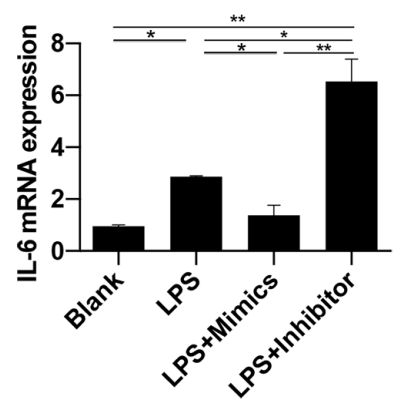

D

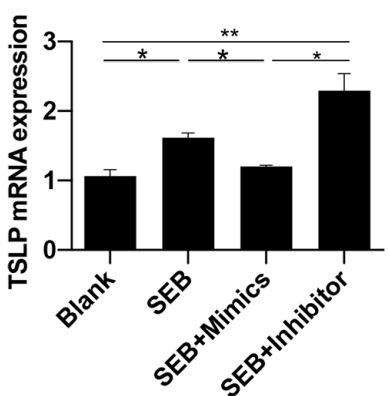

H

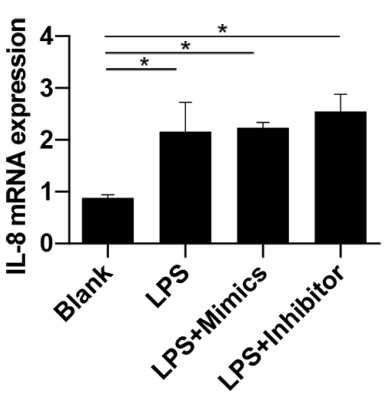

FIGURE 7 | Effect of miR-21 on cytokines in HNEpC after stimulated with SEB and LPS. Expression of (A) miR-21, (B) IL-25, (C) IL-33, and (D) TSLP were measured by qPCR in HNEpC after miR-21 transfection followed by SEB treatment. Expression of (E) miR-21, (F) IL-1 $\beta$, (G) IL-6, and (H) IL-8 were measured by qPCR in HNEpC after miR-21 transfection followed by LPS treatment. Data were obtained in three independent experiments. One-way ANOVA was used to analyze the difference between multiple groups. The asterisk indicates statistical significance, ${ }^{\star} P<0.05 ;{ }^{* \star} P<0.01 ;{ }^{* \star} P<0.001$.
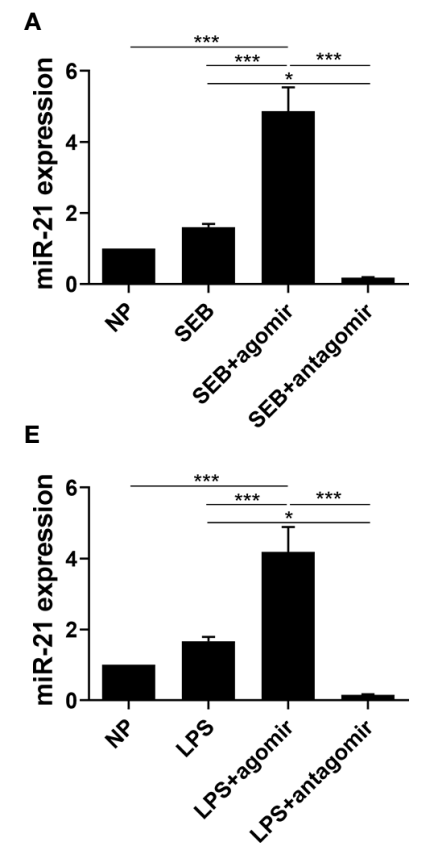

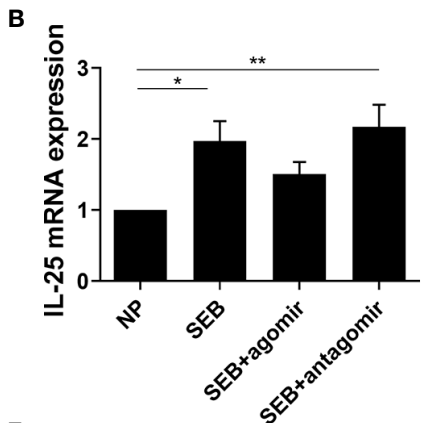

$\mathbf{F}$

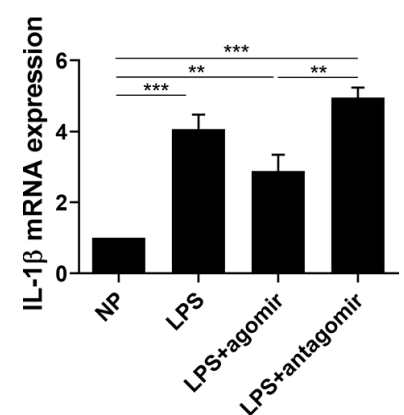

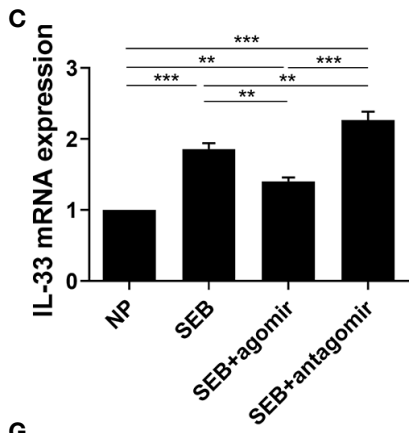

G

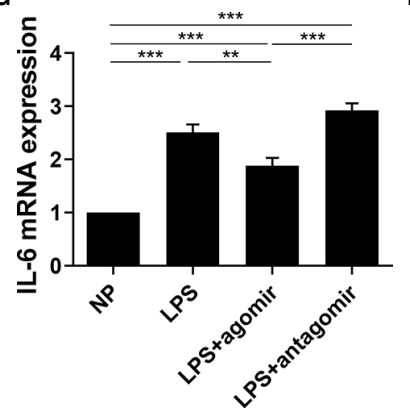

D

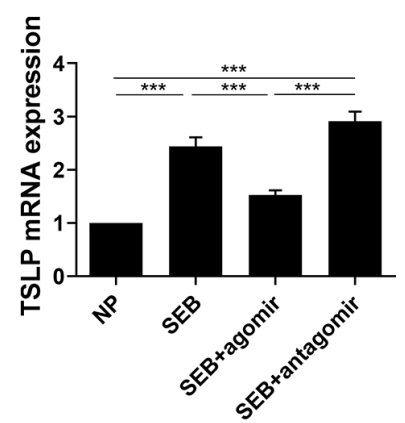

H

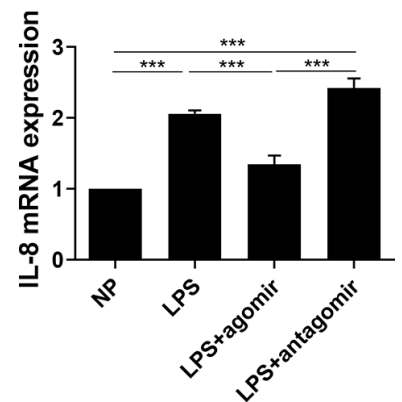

FIGURE 8 | Effect of miR-21 on cytokines in cultured nasal polyp explants after SEB or LPS treatment. Expression of (A) miR-21, (B) IL-25, (C) IL-33, and (D) TSLP were measured by qPCR in tissues after miR-21 transfection followed by SEB treatment. Expression of (E) miR-21, (F) IL-1 $\beta$, (G) IL-6, and (H) IL-8 were measured by qPCR in tissues after miR-21 transfection followed by LPS treatment. One-way ANOVA was used to analyze the difference between multiple groups. The asterisk indicates statistical significance, ${ }^{*} \mathrm{P}<0.05$; ${ }^{\star *} \mathrm{P}<0.01$; ${ }^{\star \star *} \mathrm{P}<0.001$. 

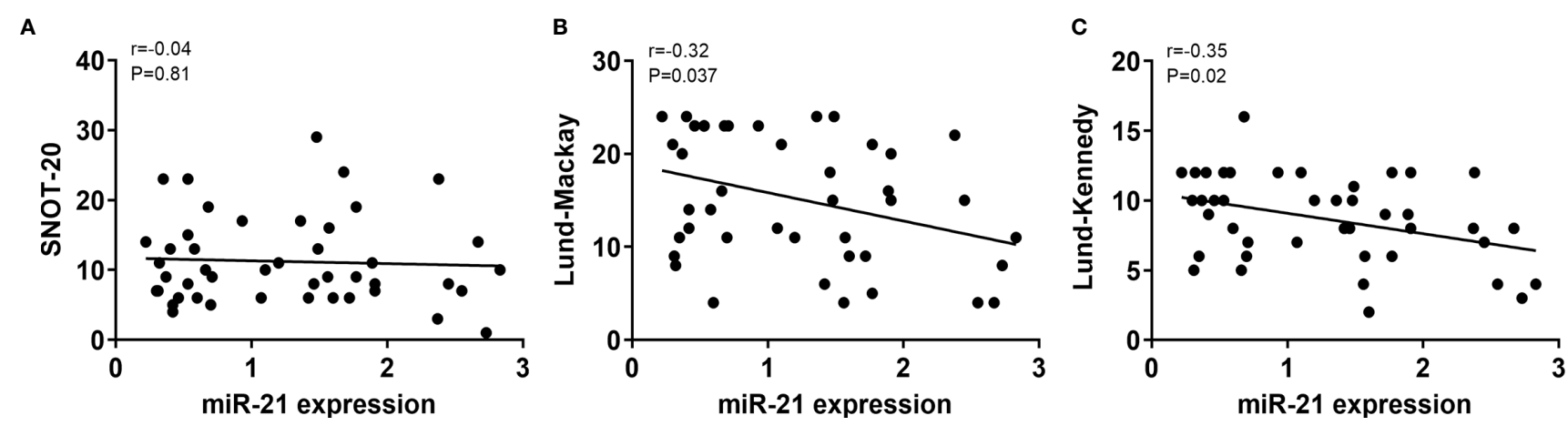

FIGURE 9 | Correlations between miR-21 expression and clinical scores. Correlations between miR-21 expression and SNOT-20 (A), Lund-Mackay (B), and LundKennedy scores (C) were investigated in CRSwNP. R-values indicate Spearman correlation coefficients.

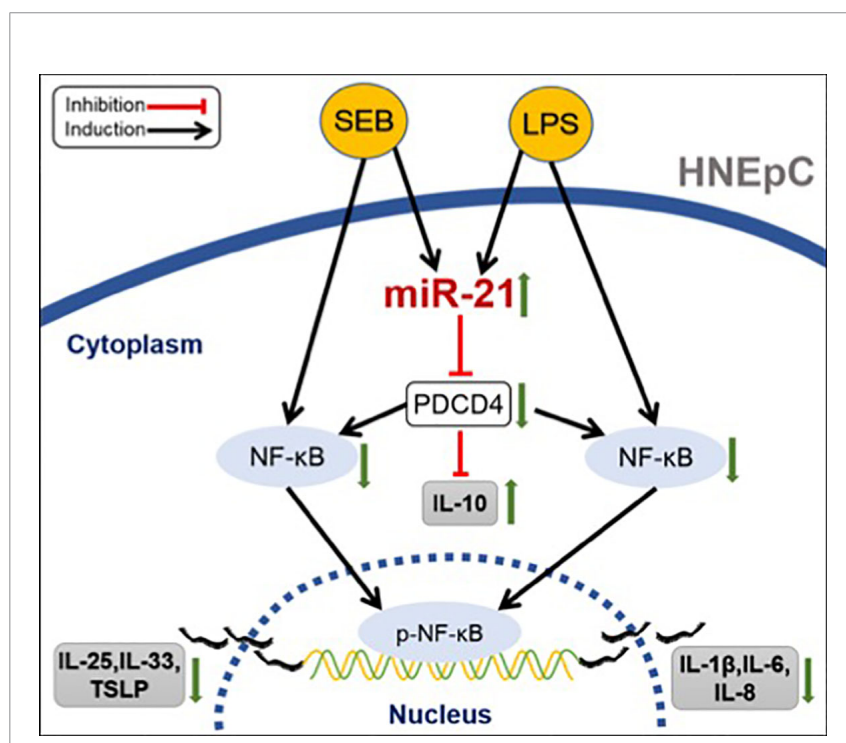

FIGURE 10 | Schematic summary of the anti-inflammatory role of miR-21. In nasal epithelial cells, SEB could promote the expression of IL-25, IL-33, and TSLP, while LPS could enhance the expression of IL-1 $1 \beta, I L-6$, and IL-8, both by activating NF- $\mathrm{KB}$. However, both SEB and LPS could upregulate miR-21 expression. Elevated miR-21 would decrease PDCD4 expression to suppress the expression of cytokines in $\mathrm{HNEpC}$ by inducing the IL-10 production and inhibiting the activation of $\mathrm{NF}-\kappa \mathrm{B}$.

inflammatory cytokine expression as well $(45,46)$. Therefore, Frederick et al. suggested that variations in the role of miR-21 may be related to the different target mRNAs engaged in different cells (21). Collectively, PDCD4 is a target gene of miR-21 in nasal epithelial cells, and miR-21 could inhibit NF- $\kappa \mathrm{B}$ activation and induce IL-10 expression via attenuating PDCD4 expression levels.

It was reported that SEB and LPS were ubiquitous toxins of pathogens in the nasal mucosa and were known to participate in the pathogenesis of NP $(47,48)$. In vitro, SEB and LPS can stimulate the release of diverse inflammatory cytokines (49-51). In this study, we chose these two agents to promote cytokine expression in the HNEpC line and ex vivo nasal polyp explants. We identified that
SEB and LPS could increase the expression of miR-21, and elevate IL-25, IL-33, TSLP, and IL-1 $\beta$, IL-6, IL-8 expression respectively. Meanwhile, the activation of NF- $\kappa \mathrm{B}$ was induced and PDCD4 protein was decreased in HNEpC after treatment with SEB or LPS in HNEpC. Sheedy et al. demonstrated that LPS could decrease PDCD4 protein via miR-21 induction (28), similar to our results.

Through increasing or inhibiting miR-21 expression in vitro and ex vivo treated with SEB or LPS, we found that the expression of pro-inflammatory cytokines could be reduced by up-regulated miR-21 yet promoted by down-regulated miR-21. Considering the pivotal role of NF- $\mathrm{KB}$ in cytokine production, we deem that miR-21 inhibits cytokines expression via the miR21/PDCD4/NF- $\mathrm{KB}$ pathway. These results indicate that miR-21 could suppress pro-inflammatory cytokine production, thereby inhibiting the development of inflammation in CRSwNP. We also observed a negative relationship between miR-21 expression and the Lund-Mackay scores or the Lund-Kennedy scores, which revealed that miR-21 may play an anti-inflammation role and be associated with the severity of CRSwNP.

In summary, we found that miR-21 could be a protective factor that inhibits the progression of inflammation. Elevated miR-21 could be a brake of inflammation involved in the development of NPs, which inferred that it might be a target in the treatment of CRSwNP.

\section{DATA AVAILABILITY STATEMENT}

All datasets generated for this study are included in the article/ Supplementary Material.

\section{ETHICS STATEMENT}

This study was approved by the Medical Ethics Committee of West China Hospital of Sichuan University (No.: WCH2015199) and was conducted to the approved institutional guidelines. The patients/participants provided their written informed consent to participate in this study. 


\section{AUTHOR CONTRIBUTIONS}

All authors listed have made a substantial, direct, and intellectual contribution to the work and approved it for publication. RL and JD contributed to the collection of data, data analysis, performed the experiments and manuscript writing. JD also contributed to the idea, experimental design, manuscript submission and revising. JZho, BZ and JZha performed the literature review and assisted in experiments. $\mathrm{LB}$ and YL contributed to the provision of study material or patient samples. SL supervised and fund the study and contributed to the final approval of the manuscript. All authors contributed to the article and approved the submitted version.

\section{REFERENCES}

1. Bachert C, Zhang L, Gevaert P. Current and future treatment options for adult chronic rhinosinusitis: Focus on nasal polyposis. J Allergy Clin Immunol (2015) 136(6):1431-40. doi: 10.1016/j.jaci.2015.10.010

2. Shi JB, Fu QL, Zhang H, Cheng L, Wang YJ, Zhu DD, et al. Epidemiology of chronic rhinosinusitis: results from a cross-sectional survey in seven Chinese cities. Allergy (2015) 70(5):533-9. doi: 10.1111/all.12577

3. Fokkens WJ, Lund VJ, Mullol J, Bachert C, Alobid I, Baroody F, et al. EPOS 2012: European Position Paper on Rhinosinusitis and Nasal Polyps 2012. A Summary for Otorhinolaryngologists. Rhinol Supplement (2012) 50(1):1-12. doi: 10.4193/Rhino50E2

4. Kato A. Immunopathology of chronic rhinosinusitis. Allergol International: Off J Japan Soc Allergol (2015) 64(2):121-30. doi: 10.1016/j.alit.2014.12.006

5. Hulse KE, Stevens WW, Tan BK, Schleimer RP. Pathogenesis of nasal polyposis. Clin Exp Allergy: J Br Soc Allergy Clin Immunol (2015) 45 (2):328-46. doi: 10.1111/cea.12472c

6. Liao B, Cao PP, Zeng M, Zhen Z, Wang H, Zhang YN, et al. Interaction of thymic stromal lymphopoietin, IL-33, and their receptors in epithelial cells in eosinophilic chronic rhinosinusitis with nasal polyps. Allergy (2015) 70 (9):1169-80. doi: 10.1111/all.12667

7. Otto BA, Wenzel SE. The role of cytokines in chronic rhinosinusitis with nasal polyps. Curr Opin Otolaryngol Head Neck Surg (2008) 16(3):270-4. doi: 10.1097/MOO.0b013e3282fb2885

8. Stevens WW, Lee RJ, Schleimer RP, Cohen NA. Chronic rhinosinusitis pathogenesis. J Allergy Clin Immunol (2015) 136(6):1442-53. doi: 10.1016/ j.jaci.2015.10.009

9. Park SJ, Kim TH, Jun YJ, Lee SH, Ryu HY, Jung KJ, et al. Chronic rhinosinusitis with polyps and without polyps is associated with increased expression of suppressors of cytokine signaling 1 and 3. J Allergy Clin Immunol (2013) 131(3):772-80. doi: 10.1016/j.jaci.2012.12.671

10. Moore KW, de Waal Malefyt R, Coffman RL, O'Garra A. Interleukin-10 and the interleukin-10 receptor. Annu Rev Immunol (2001) 19:683-765. doi: 10.1146/annurev.immunol.19.1.683

11. Muller B, de Groot EJ, Kortekaas IJ, Fokkens WJ, van Drunen CM. Nasal epithelial cells express IL-10 at levels that negatively correlate with clinical symptoms in patients with house dust mite allergy. Allergy (2007) 62(9):101422. doi: 10.1111/j.1398-9995.2007.01419.x

12. Ambros V. The functions of animal microRNAs. Nature (2004) 431 (7006):350-5. doi: 10.1038/nature02871c

13. Bushati N, Cohen SM. microRNA functions. Annu Rev Cell Dev Biol (2007) 23:175-205. doi: 10.1146/annurev.cellbio.23.090506.123406

14. Sonkoly E, Stahle M, Pivarcsi A. MicroRNAs and immunity: Novel players in the regulation of normal immune function and inflammation. Semin Cancer Biol (2008) 18(2):131-40. doi: 10.1016/j.semcancer.2008.01.005

15. Zhang XH, Zhang YN, Li HB, Hu CY, Wang N, Cao PP, et al. Overexpression of miR-125b, a novel regulator of innate immunity, in eosinophilic chronic rhinosinusitis with nasal polyps. Am J Respir Crit Care Med (2012) 185 (2):140-51. doi: 10.1164/rccm.201103-0456OC

\section{FUNDING}

This study was supported by the National Natural Science Fund of China (81970858, 81570900 and 81271058), which supplies the most of funds for the study. Moreover, this study was also supported by the National Natural Science Fund of China (81860186).

\section{SUPPLEMENTARY MATERIAL}

The Supplementary Material for this article can be found online at: https://www.frontiersin.org/articles/10.3389/fimmu.2021. 530488/full\#supplementary-material

16. Zhang XH, Zhang YN, Liu Z. MicroRNA in chronic rhinosinusitis and allergic rhinitis. Curr Allergy Asthma Rep (2014) 14(2):415. doi: 10.1007/s11882013-0415-3

17. Xia G, Bao L, Gao W, Liu S, Ji K, Li J. Differentially Expressed miRNA in Inflammatory Mucosa of Chronic Rhinosinusitis. J Nanosci Nanotechnol (2015) 15(3):2132-9. doi: 10.1166/jnn.2015.9161

18. Li L, Feng J, Zhang D, Yong J, Wang Y, Yao J, et al. Differential expression of miR-4492 and IL-10 is involved in chronic rhinosinusitis with nasal polyps. Exp Ther Med (2019) 18(5):3968-76. doi: 10.3892/etm.2019.8022

19. Loboda A, Sobczak M, Jozkowicz A, Dulak J. TGF-beta1/Smads and miR-21 in Renal Fibrosis and Inflammation. Mediators Inflammation (2016) 2016:8319283. doi: 10.1155/2016/8319283

20. Kumarswamy R, Volkmann I, Thum T. Regulation and function of miRNA-21 in health and disease. RNA Biol (2011) 8(5):706-13. doi: 10.4161/rna.8.5.16154

21. Sheedy FJ. Turning 21: Induction of miR-21 as a Key Switch in the Inflammatory Response. Front Immunol (2015) 6:19. doi: 10.3389/fimmu.2015.00019

22. Lu TX, Munitz A, Rothenberg ME. MicroRNA-21 is up-regulated in allergic airway inflammation and regulates IL-12p35 expression. J Immunol (Baltimore Md: 1950) (2009) 182(8):4994-5002. doi: 10.4049/ jimmunol.0803560

23. Elbehidy RM, Youssef DM, El-Shal AS, Shalaby SM, Sherbiny HS, Sherief LM, et al. MicroRNA-21 as a novel biomarker in diagnosis and response to therapy in asthmatic children. Mol Immunol (2016) 71(undefined):107-14. doi: 10.1016/j.molimm.2015.12.015

24. Chen RF, Huang HC, Ou CY, Hsu TY, Chuang H, Chang JC, et al. MicroRNA-21 expression in neonatal blood associated with antenatal immunoglobulin E production and development of allergic rhinitis. Clin Exp Allergy: J Br Soc Allergy Clin Immunol (2010) 40(10):1482-90. doi: 10.1111/j.1365-2222.2010.03592.x

25. Cao PP, Li HB, Wang BF, Wang SB, You XJ, Cui YH, et al. Distinct immunopathologic characteristics of various types of chronic rhinosinusitis in adult Chinese. J Allergy Clin Immunol (2009) 124(3):478-84. doi: 10.1016/ j.jaci.2009.05.017

26. Ba L, Zhang N, Meng J, Zhang J, Lin P, Zhou P, et al. The association between bacterial colonization and inflammatory pattern in Chinese chronic rhinosinusitis patients with nasal polyps. Allergy (2011) 66(10):1296-303. doi: 10.1111/j.1398-9995.2011.02637.x

27. Du J, Zhang X, Cao H, Jiang D, Wang X, Zhou W, et al. MiR-194 is involved in morphogenesis of spiral ganglion neurons in inner ear by rearranging actin cytoskeleton via targeting RhoB. Int J Dev Neurosci: Off J Int Soc Dev Neurosci (2017) 63:16-26. doi: 10.1016/j.ijdevneu.2017.09.004

28. Sheedy FJ, Palsson-McDermott E, Hennessy EJ, Martin C, O'Leary JJ, Ruan Q, et al. Negative regulation of TLR4 via targeting of the proinflammatory tumor suppressor PDCD4 by the microRNA miR-21. Nat Immunol (2010) 11 (2):141-7. doi: $10.1038 /$ ni.1828

29. Das A, Ganesh K, Khanna S, Sen CK, Roy S. Engulfment of apoptotic cells by macrophages: a role of microRNA-21 in the resolution of wound inflammation. I Immunol (Baltimore Md: 1950) (2014) 192(3):1120-9. doi: $10.4049 /$ jimmunol.1300613 
30. Corsetti PP, de Almeida LA, Gonçalves ANA, Gomes MTR, Guimarães ES, Marques JT, et al. Brucella abortusmiR-181a-5p Regulates TNF- $\alpha$ and miR21a-5p Influences Gualynate-Binding Protein 5 and IL-10 Expression in Macrophages Affecting Host Control of Infection. Front Immunol (2018) 9:1331. doi: 10.3389/fimmu.2018.01331

31. Jiang Y, Gao Q, Wang L, Guo C, Zhu F, Wang B, et al. Deficiency of programmed cell death 4 results in increased IL-10 expression by macrophages and thereby attenuates atherosclerosis in hyperlipidemic mice. Cell Mol Immunol (2016) 13(4):524-34. doi: 10.1038/cmi.2015.47

32. Stevens WW, Schleimer RP, Kern RC. Chronic Rhinosinusitis with Nasal Polyps. J Allergy Clin Immunol Pract (2016) 4(4):565-72. doi: 10.1016/j.jaip.2016.04.012

33. Bachert C, van Zele T, Gevaert P, De Schrijver L, Van Cauwenberge P. Superantigens and nasal polyps. Curr Allergy Asthma Rep (2003) 3(6):523-31. doi: 10.1007/s11882-003-0065-y

34. Lan F, Zhang N, Holtappels G, Ruyck N, Krysko O, Crombruggen KV, et al. Staphylococcus aureus Induces Mucosal Type 2 Immune Response via Epithelial Cell Derived Cytokines. Am J Respir Crit Care Med (2018) 198 (4):452-63. doi: 10.1164/rccm.201710-2112OC

35. Damm M, Quante G, Rosenbohm J, Rieckmann R. Proinflammatory effects of Staphylococcus aureus exotoxin B on nasal epithelial cells. Otolaryngol-head Neck Surg: Off J Am Acad Otolaryngol-Head Neck Surg (2006) 134(2):245-9. doi: 10.1016/j.otohns.2005.11.016

36. Sun C, Tian J, Liu X, Guan G. MiR-21 promotes fibrosis and hypertrophy of ligamentum flavum in lumbar spinal canal stenosis by activating IL-6 expression. Biochem Biophys Res Commun (2017) 490(3):1106-11. doi: 10.1016/j.bbrc.2017.06.182

37. Ando Y, Yang GX, Kenny TP, Kawata K, Zhang W, Huang W, et al. Overexpression of microRNA-21 is associated with elevated proinflammatory cytokines in dominant-negative TGF-beta receptor type II mouse. J Autoimmun (2013) 41:111-9. doi: 10.1016/j.jaut.2012.12.013

38. Case SR, Martin RJ, Jiang D, Minor MN, Chu HW. MicroRNA-21 inhibits toll-like receptor 2 agonist-induced lung inflammation in mice. Exp Lung Res (2011) 37(8):500-8. doi: 10.3109/01902148.2011.596895

39. Cohen TS, Prince AS. Bacterial pathogens activate a common inflammatory pathway through IFN $\lambda$ regulation of PDCD4. PloS Pathog (2013) 9(10): e1003682. doi: 10.1371/journal.ppat.1003682

40. Valera FC, Queiroz R, Scrideli C, Tone LG, Anselmo-Lima WT. Expression of transcription factors NF-kappaB and AP-1 in nasal polyposis. Clin Exp Allergy: J Br Soc Allergy Clin Immunol (2008) 38(4):579-85. doi: 10.1111/ j.1365-2222.2007.02929.x

41. Plewka D, Grzanka A, Drzewiecka E, Plewka A, Misiolek M, Lisowska G, et al. Differential expression of tumor necrosis factor alpha, interleukin 1beta, nuclear factor kappaB in nasal mucosa among chronic rhinosinusitis patients with and without polyps. Postepy Dermatol Alergol (2017) 34 (3):199-206. doi: 10.5114/ada.2017.67842

42. Takeno S, Hirakawa K, Ueda T, Furukido K, Osada R, Yajin K. Nuclear factorkappa $\mathrm{B}$ activation in the nasal polyp epithelium: relationship to local cytokine gene expression. Laryngoscope (2002) 112(1):53-8. doi: 10.1097/00005537200201000-00010

43. Ando Y, Yang GX, Kenny TP, Kawata K, Zhang W, Huang W, et al. Overexpression of microRNA-21 is associated with elevated proinflammatory cytokines in dominant-negative TGF- $\beta$ receptor type II mouse. J Autoimmun (2013) 41:111-9. doi: 10.1016/j.jaut.2012.12.013

44. Shi C, Yang Y, Xia Y, Okugawa Y, Yang J, Liang Y, et al. Novel evidence for an oncogenic role of microRNA-21 in colitis-associated colorectal cancer. Gut (2016) 65(9):1470-81. doi: 10.1136/gutjnl-2014-308455

45. Wang X, Zhang L, Wei Z, Zhang X, Gao Q, Ma Y, et al. The inhibitory action of PDCD4 in lipopolysaccharide/D-galactosamine-induced acute liver injury. Lab Investigation J Tech Methods Pathol (2013) 93(3):291-302. doi: 10.1038/ labinvest.2012.174

46. Wang L, Zhao M, Guo C, Wang G, Zhu F, Wang J, et al. PDCD4 Deficiency Aggravated Colitis and Colitis-associated Colorectal Cancer Via Promoting IL-6/STAT3 Pathway in Mice. Inflammatory Bowel Dis (2016) 22(5):1107-18. doi: $10.1097 / \mathrm{mib} .0000000000000729$

47. Patou J, Gevaert P, Van Zele T, Holtappels G, van Cauwenberge P, Bachert C. Staphylococcus aureus enterotoxin B, protein $\mathrm{A}$, and lipoteichoic acid stimulations in nasal polyps. J Allergy Clin Immunol (2008) 121(1):110-5. doi: 10.1016/j.jaci.2007.08.059

48. Wang S, Zhang H, Xi Z, Huang J, Nie J, Zhou B, et al. Establishment of a mouse model of lipopolysaccharide-induced neutrophilic nasal polyps. Exp Ther Med (2017) 14(6):5275-82. doi: 10.3892/etm.2017.5208

49. Kim DW, Eun KM, Jin HR, Cho SH, Kim DK. Prolonged allergen exposure is associated with increased thymic stromal lymphopoietin expression and Th2skewing in mouse models of chronic rhinosinusitis. Laryngoscope (2016) 126 (8):E265-72. doi: 10.1002/lary.26004

50. Cho JS, Kang JH, Um JY, Han IH, Park IH, Lee HM. Lipopolysaccharide induces pro-inflammatory cytokines and MMP production via TLR4 in nasal polyp-derived fibroblast and organ culture. PloS One (2014) 9(11):e90683. doi: 10.1371/journal.pone.0090683

51. Wang W, Xu X, Zheng M, Wan L. Lipopolysaccharides induces MUC5AC overproduction in human nasal epithelium. Eur Arch Otorhinolaryngol (2013) 270(2):541-7. doi: 10.1007/s00405-012-2037-0

Conflict of Interest: The authors declare that the research was conducted in the absence of any commercial or financial relationships that could be construed as a potential conflict of interest.

Copyright $\odot 2021 \mathrm{Liu}, \mathrm{Du}$, Zhou, Zhong, Ba, Zhang, Liu and Liu. This is an openaccess article distributed under the terms of the Creative Commons Attribution License (CC BY). The use, distribution or reproduction in other forums is permitted, provided the original author(s) and the copyright owner(s) are credited and that the original publication in this journal is cited, in accordance with accepted academic practice. No use, distribution or reproduction is permitted which does not comply with these terms. 